\title{
Maternal state affects intestinal changes of rat pups at weaning
}

Montserrat Gomendio 1,2 , Jorge Cassinello ${ }^{1}$, Michael W. Smith ${ }^{3}$ \& Patrick Bateson ${ }^{1}$

${ }^{1}$ Sub-Department of Animal Behaviour, University of Cambridge, High Street, Madingley, Cambridge, CB3 8AA, UK

2Departamento de Ecología Evolutiva, Museo Nacional de Ciencias

Naturales (C.S.I.C.), Jose Gutierrez Abascal 2, 28006 Madrid, Spain

3Institute of animal Physiology and Genetics Research, Babraham, Cambridge CB2 4AT, UK

Correspondence should be sent to:

M. Gomendio

Sub-Department of Animal Behaviour

University of Cambridge

Madingley

Cambridge CB3 8AA

Telephone: + (954) 210301

Fax: $\quad+$ (954) 210247

E. Mail: mg117@phx.cam.ac.uk 
Abstract. Two treatments of hooded rat mothers after the birth of their pups affected the stage of development at which their pups started to take solid food and showed an increase in the expression of sucrase, an enzyme needed for digesting solid food. The pups of mothers that became pregnant in a post-partum oestrus showed the changes significantly earlier than those in the control group (Fig. 1a \& b). The pups of mothers that had been mildly food-restricted after birth showed the changes significantly later than those in the control group. In brief, the pups of the Pregnant mothers weaned first, the Control pups next and those of Food-Restricted mothers weaned last. Differences in the timing of weaning between the three groups occurred in the absence of differences in pup body weight at the time of weaning. Within each experimental group, on the day in which sucrase expression showed the first detectable increase, sucrase activity was strongly predicted by the weight of the pups shortly after birth (Fig. 3). Pregnant mothers put on weight rapidly before implantation and their pups prepared for early weaning even though they did not differ in body weight from Control pups (Fig. 4a \& b). Food-restricted mothers were significantly lighter than Control mothers and, with lighter pups before weaning started, settled for a longer period of suckling.

Key words: Weaning - Sucrase - Hooded rat -Growth rates - Parentoffspring conflict 


\section{Introduction}

In most mammalian species, females provide all the care that young offspring need. Both gestation and lactation are expensive in energetic terms, but the costs of producing milk are particularly high (Martin 1984; Oftedal 1984; Prentice and Whitehead 1987) The energetic costs of lactation are of such magnitude that they affect the mothers' subsequent fecundity and survival (Altmann 1983; Clutton-Brock et al. 1989; Gomendio et al. 1990; Gomendio 1991; see also Fuchs 1981, 1982). On the other hand, the timing of weaning has been shown to influence the growth of offspring; and early termination of lactation markedly reduces their survival and the subsequent reproductive success of the survivors (Fuchs 1981; Clutton-Brock et al. 1982; Clutton-Brock et al. 1988; Green and Rothstein 1991; Festa-Bianchet et al. 1994)

Evolutionary theory has been used to predict that, in order to maximise their lifetime reproductive success, females should balance the benefits of caring for present offspring against the costs to their own future reproduction (Trivers 1974) . Since mothers suffer high costs while lactating, the timing of weaning is critical, particularly among small mammals where the energetic costs are relatively high and life span tends to be short. A rule should have evolved so that mothers are able to balance the costs to their own future reproduction against the benefits of continued lactation on offspring survival or offspring reproductive success. In some of the mammalian species studied so far, the timing of weaning shows a remarkable degree of flexibility suggesting that, far from being fixed, mothers can vary the length of lactation substantially (Berger 1979; Collinge 1987; König and Mark1 1987; Babbitt and Packard 1990; Trillmich 1990; Gomendio 1991), but see (Krackow 1989) . Food availability can influence the timing of weaning in rodents, ungulates, primates and marine mammals (Berger 
1979; Lee 1987; Babbitt and Packard 1990; Smith 1991; Green and Griswold 1993; Hauser 1993). In general, mothers tend to extend lactation when food resources are scarce thereby increasing the likelihood of offspring survival when growth rates are slow. The mothers do this even though it may delay their next reproductive attempt. When conditions deteriorate beyond a certain point, they tend to withdraw their care and wait for conditions to improve before they reproduce again. Similarly, in species which produce several offspring per litter, lactation is extended when mothers produce large litters in order to compensate for the reduction in growth rates suffered by individual offspring (Cameron 1973; König and Markl 1987) In contrast, when mothers mate at the post-partum oestrus and have to cope with the energetic costs of gestation and lactation simultaneously, they do not extend lactation and wean offspring at a smaller size (König and Markl 1987) .

Trivers (1974) pointed out that, from an evolutionary perspective, the long-term interests of the parent are not identical with those of their offspring. A parent may increase its reproductive success by weaning its young earlier than is best for them, because it saves itself from becoming too exhausted and is thus able to have a larger number of offspring than would otherwise have been the case. As a consequence, aggression between parents and offspring is expected, particularly at the time of weaning. Trivers stimulating contribution has been responsible for a large theoretical literature (reviewed by Mock and Forbes 1992). However, the insights derived from evolutionary theory have been questioned recently in part because of changes in theoretical stance about the benefits of reliable signals. Godfray (1991) has used honest signalling theory to argue that, as long as solicitation is costly, offspring may benefit from communicating reliable information to their parents 
about their physical condition and parents should allocate resources accordingly.

Trivers' evolutionary argument led to an unjustified expectation that conflict of evolutionary interest necessarily implies behavioural conflict. Mock and Forbes (1992) suggested that behavioural aggression between parent and offspring should be referred to as "squabbling", thus avoiding the punning use of "conflict". Much evidence now suggests, however, that squabbling often does not occur at all and, if it does, is seen at quite different stages in development from the one at which the process of weaning occurs (Altmann 1983; Martin 1986; König and Markl 1987; Gomendio 1991; Smith 1991) . Mothers do not always force independence on offspring, and offspring show clear shifts towards a preference for solid food, even when given the choice between this and a lactating female (Thiels et al. 1988). Given this evidence, it is remarkable that the offspring's point of view has seldom been taken into account. In particular, the idea that offspring may need to use cues provided by its mother in order to maximise its own chances of survival has so far received little attention. In altricial species, offspring undergo a series of complex behavioural and physiological changes before weaning can take place and, since the timing of weaning may vary, offspring would benefit from timing these changes carefully. The young may have to pay attention to the condition of the mother because of the need to take into account both the immediate effects of maternal care on survival but also the post-weaning contributions of the mother (Bateson 1994) . Furthermore, preparation for weaning in the young requires many changes in the gut (reviewed in (Henning 1981, 1989) . A constraint on how rapidly the metamorphosis of the intestinal anatomy and physiology can take place may require that offspring pay attention to cues from the mother. 
In altricial rodents weaning is preceded by major developmental changes. Before the transition to solid food begins, eyes and ears open, teeth increase dramatically in size, and mechanisms of thermal homeostasis and regulation of food intake mature. In addition, the change in diet from milk to solid food requires major changes in digestive mechanisms. In particular, the presence (or level of activity) of digestive enzymes changes in most parts of the alimentary tract. The degree of co-ordination between changes at different levels and in different parts of the digestive system is remarkable, leading to the suggestion that all these processes may be under the control of one (or a few) factors. Many physiologists suppose that the intestinal changes are under intrinsic control (Henning 1989; Johnson 1989) . It seems unlikely, though, that given the variability in the timing of weaning, physiological changes necessary for weaning occur at a fixed stage in development. Pups that were weaned early would not be physiologically ready to process solid food and would thus experience high mortality rates or at least considerable weight loss. Pups that were weaned late would not be able to benefit from this extra maternal care since their digestive systems would have been prepared to ingest solid food and would no longer be able to digest milk efficiently. More plausibly, pups should respond to cues provided by their mothers and time intestinal changes accordingly. The experiment described in this paper was designed to test this possibility.

In this study the timing of weaning was examined by manipulating factors that are known to influence the timing of weaning in wild, as well as captive, populations. Pups of hooded rat mothers in a control group were compared with those of mothers that were food restricted and those that were mated again shortly after the birth of the pups. Previous work had suggested that both these manipulations would affect the behaviour 
of the mother towards her pups (Smith 1991). We anticipated that food restricted mothers would delay weaning in relation to control mothers because it would pay them to extend care in order to compensate for the slower growth rates of their pups. Pregnant mothers, on the other hand were expected to wean earlier in order to prepare for the new litter.

\section{Methods}

The laboratory rat was chosen as the subject of this study because so much is known about this animal's post-natal development from behavioural, physiological and biochemical studies. Lister Hooded rats were purchased from commercial suppliers (Harlan Olac Ltd, Oxfordshire). They were subsequently bred from laboratory stocks and further lots of rats were purchased throughout the study in order to avoid inbreeding. Females were kept individually in standard polycarbonate cages $(56 \mathrm{~cm} \times 38 \mathrm{~cm} \times 18 \mathrm{~cm})$, on ad libitum food pellets and tap water. Light was on a 12:12 h light:dark cycle and temperature was thermostatically maintained at $21^{\circ} \mathrm{C}$. Oestrus was detected by vaginal smears.

Females in oestrus were paired with an adult male and the following morning vaginal smears were used to check that there were spermatozoa in the female tract. After mating, females in the Control and the Food Restricted group were placed in individual cages throughout pregnancy and lactation. Females that were mated at the post-partum oestrus remained with the male until 24 hours after birth. Food restricted females received $75 \%$ of the normal food intake (see Table I). In order to determine the average amount of food eaten by Control females at different reproductive stages, the amount of food provided and the amount that was left uneaten were weighed daily throughout pregnancy and lactation. Average values were obtained every 
3 days. Since Control mothers increased markedly the amount of food ingested throughout lactation, Food Restricted mothers received increasing amounts of food. Food restriction started on day 3 of lactation in order to prevent mothers from cannibalising the entire litter. The day of birth was considered as day 0 . Pups were weighed and sexed on day 0 and were left undisturbed until day 3 . From then on pups were marked with a non-toxic pen to allow individual recognition. Pups were marked and weighed individually daily until weaning.

To estimate the developmental stage of the pups' gut, we used sucrase activity. This enzyme cannot be detected during the early suckling period and its activity can be detected for the first time approximately on day 17 , i.e. around weaning. From then on the level of sucrase activity increases until it reaches adult levels by the middle of the fourth week (Henning 1981) . Having such a distinctive developmental curve and being easy to assay, sucrase has been widely used in studies of intestinal development. The presence of this enzyme is essential when pups change from a diet based on milk which has lactose and its derivatives as sole carbohydrates to one that has starch and sucrose as principal carbohydrates. Pups from 12 to 21 days old were sacrificed by cervical dislocation and samples were obtained immediately thereafter (see Table II). From each litter 2 to 4 pups were chosen according to the following criteria: when 2 pups were sacrificed one male and one female whose body weight was closest to the litter average were chosen; when four pups were sacrificed, two of them were chosen according to the previous criteria and the other two were the pups whose body weights were the heaviest and lightest of the litter.

The method used to perform the assays was as follows. Mucosal scraping obtained from the small intestine of pups, stored at $-40^{\circ} \mathrm{C}$ until ready for assay, were disrupted by sonication in $0.5 \mathrm{ml} \mathrm{H}_{2} \mathrm{O}(5 \mathrm{sec}$ at full 
power, ultrasonic processor, Heat Systems - Ultrasonic Inc.). Aliquots of these sonicates were then incubated at $37^{\circ} \mathrm{C}$ for 60 min with $90 \mathrm{mM}$ sucrose, $4 \mathrm{mM}$ disodium succinate buffer, $\mathrm{pH}$ 6.0, as described by Dahlquist (1960) . Glucose released by hydrolysis of sucrose in that experiment was then estimated using the glucose oxidase kit of Boehringer. Further aliquots of each sonicate were used to estimate tissue protein as described by Markwell et al. (1978) All estimates were performed in duplicate. Final results for sucrase activities are given as $\mu$ moles glucose produced/mg protein/60 min incubation.

For some litters stomach contents were also analysed. It was possible to determine the relative amounts of milk and solid food present in the stomach by visual inspection. When the stomachs were opened the milk (white) could be clearly distinguished from the solid food (brownish) by its colour and texture. The proportion of solid food present in the stomach was categorised using the following index: $0=$ no solid food; $1=$ less than $50 \%$ solid food; $2=$ some milk but more than $50 \%$ of solid food; and 3 = solid food exclusively.

When litter size is greater than one, the data for each pup may not be independent from its siblings. In such cases average values for each litter should be used in statistical analyses (Abbey and Howard 1973) . This procedure may, however, obscure individual differences within litters which, at least in this study, were considerable. Intra-litter variation was compared with inter-litter variation using a one-way ANOVA. Although siblings differed substantially in body weight (for example, at 20 days two pups from the same litter weighed 20.51 and $41.44 \mathrm{~g}$ respectively), inter-litter variation was even greater. Thus, we obtained average values for each litter. When analysing sucrase activity, however, intra-litter variation was greater than inter-litter variation, thus justifying the treatment of each pup as an independent data point. The 
sucrase data were not normally distributed so we performed statistical analyses after adding one (because some of the values were zero) and taking the reciprocal. In some cases in which we wished to pool data from groups that differed statistically from each other, we standardised the scores for each group. This converted the mean for that group to zero with a standard deviation of 1.0.

Cases in which mothers mated at the post-partum oestrus but failed to deliver a litter were excluded from the analyses. So were cases in which mothers produced litters with fewer than three pups.

\section{Results}

The hooded rat pups relied entirely on maternal milk during the first 16 days of life. No solid food was found in the stomachs of pups younger than 17 days in any group. The results for days 17-21 are shown in Figure 1a. Some pups of Control mothers started ingesting solid food when they were 18 days old, and the proportion of solid food present in the stomach increased until day 21 when milk was no longer found. No information is available for pups born to Food Restricted mothers on days 17 and 18. By day 19 some pups in this group had a small proportion of solid food, but many had none at all. On days 20 and 21 the proportion of solid food present in the stomach increased but at all ages it remained significantly lower than in the Control group. Pups born to mothers in the Pregnant group started ingesting solid food on day 18 and the proportion of solid food was significantly higher on days 19 and 20 than for pups in the Control group. Throughout the age range considered, pups in the Pregnant group showed significantly greater proportions of solid food than did pups in the Control group until day 21 when no milk was found in either of the two groups. 
Slight sucrase activity was detected only twice in pups aged 17 days. The results for Days 17-21 are shown in Figure 1b. In the Control group, pups showed low levels of sucrase activity on day 18 and these levels increased slowly until day 21 when sucrase activity showed a sudden increase. Pups of Food Restricted mothers showed the first signs of sucrase activity on day 19 and had very low levels even on day 21 . In contrast, pups in the Pregnant group showed the first signs of sucrase activity on day 18 and activity levels increased sharply on day 19, remaining higher than in the other two groups from then on. In summary, within the day 18-20 range, pups born to Food restricted mothers had significantly lower levels of sucrase activity than Control pups, while pups born to Pregnant mothers had significantly higher levels of sucrase activity.

A strong correlation was found between the amount of food present in the stomach and sucrase activity (Figure 2). In 31 cases slight sucrase activity was detected in the absence of food, and in 7 cases no sucrase activity was detected when food was present in the stomach.

Although the differences between the three experimental groups in terms of sucrase activity were clear, substantial variation was found within each group at each age. The heaviest pup in each litter expressed significantly more sucrase than the lightest pup in each litter (A 3-way ANOVA on transformed sucrase scores gave Pup weight $F=13.56, d f=$ $1,52, P<0.002$ for this factor with Age $F=41.64$ and Group $F=51.60$ both very highly significant and with none of the interactions being significant). Within each experimental group, on the day in which the sucrase scores showed the first detectable increase (day 20 for the Control and Food Restricted groups and Day 18 for the Pregnant group), sucrase activity was correlated with the weight of the pups (see Table 3). In order to increase the sample sizes, the sucrase activities and weights 
for each group were standardised and then combined with those of the other groups. The weight of the pups on the first day in which sucrase activity underwent an increase was strongly correlated with levels of sucrase activity (rho=0.73, $\mathrm{p}<0.0001)$. Even pup weight measured three days after birth correlated with sucrase activity when weaning starts, as may be seen in Figure 3. The relationship between pup body weight and sucrase activity weakens (as in the Food restricted group) or disappears (as in the pregnant group) as weaning progresses partly because, once weaning has started, light pups start to show enzymatic activity even if they have low body weights. Despite the within group correlations between weight and sucrase activity, the marked differences found in the timing of the appearance of solid food and in the developmental curve of sucrase activity between the three experimental groups occurred in the absence of differences in pup body weight around the time when these changes took place (Table IV).

Pup weights are shown in Figure 4a. They did not differ at birth and throughout lactation no overall differences were found between the three experimental groups. Pups in the Pregnant group showed a nonsignificant trend to put on weight more rapidly up to the onset of weaning. Pups in the Food-restricted group put on weight least rapidly and were significantly lighter than the Control group soon after food restriction started and just before weaning.

Maternal weights are shown in Figure $4 b$. They did not differ between the three experimental groups on day of birth, but significant differences emerged throughout lactation. Control mothers lost some weight before day 3 but from then on maternal body weight increased slowly but steadily until day 17 when mothers experienced a marked gain in body weight which coincided with the onset of weaning. Food restriction started on day 3 and so differences between the Control group 
and the Food Restricted group did not emerge until later. During the week following birth, Food Restricted mothers showed a marked decline in body weight which was followed by a period of stability until pups were 17 days old after which these mothers recovered their original body weight. The weight of food restricted mothers was significantly lower than that of Control mothers. Mothers in the Pregnant group experienced the greatest increases in body weight throughout lactation, but these differences did not reach statistical significance.

Females gave birth to about 10 to 11 pups on average (see Figure 5). Litter size decreased in all three experimental groups, particularly during the second week of life. The groups did not differ significantly in the extent to which litter sizes were reduced. It was not clear whether mothers actively killed pups of whether pup deaths were due to undernourishment caused by maternal neglect or competition with their siblings. Pups were often partially or totally consumed by their mothers making it difficult to determine the cause of death. In those instances in which dead pups were found they showed no signs of injuries suggesting that they died of neglect.

\section{Discussion}

Two different treatments of rat mothers after the birth of their pups significantly affected the stage of development at which their pups started to take solid food and the stage at which they first expressed intestinal sucrase, a digestive enzyme required for processing solid food. Pups of pregnant mothers showed the changes significantly earlier than those in the control group. Pups of mothers that had been mildly foodrestricted after birth showed the changes significantly later than those in the control group. The presence of solid food was strongly associated with the increase in the expression of sucrase. 
When planning the study, we had anticipated that the gut should be prepared for the changes in the intake of food that occur at weaning. The hypothesis that manipulations of the mother's state would affect the timing of events leading to changes in the gut appears to be correct. The experimental treatments led to differences in maternal body weight but mothers buffered their pups so effectively that few differences in pup body weight could be found. Differences in the timing of the shift to solid food and the appearance of sucrase between the three experimental groups occurred in the absence of differences in pup body weight around weaning. Before weaning, significant differences were only found between pups born to Food restricted mothers and Control pups soon after food restriction started and just before the onset of weaning. However, within each experimental group, the heaviest pup in each litter showed higher solid food scores and sucrase values when weaning started than the lightest pup. This was corroborated by the correlation between pup body weight and sucrase values for each group on the day when weaning started. Therefore, the stage of development of the pup as measured by its weight had some influence on the onset of the weaning process within each experimental group, but not between groups. As weaning progressed the relationship between pup body weight and sucrase activity weakened partly because lighter pups followed the lead of heavier pups and started to show sucrase activity despite their low body weights. In other words, pups were weaned at very different weights.

The earliest age at which sucrase activity was detected was in pups aged 17 days old; even very heavy pups did not show sucrase activity at younger ages. This finding suggests that sucrase activity cannot be expressed until a critical stage in development has been reached and agrees with earlier findings (Henning 1981). Previous studies had found 
that when pups were prevented from gaining access to solid food, sucrase activity was expressed around day 18, showing that the ingestion of solid food is not a necessary prerequisite for changes in the gut (Henning 1989; Johnson 1989). However, our results also suggest that the pups of the food restricted mothers significantly delayed the expression of sucrase. Henning (1989) and Johnson (1989) . may have been led to the conclusion that the timing of changes in the gut could not be delayed beyond a given age because they did not manipulate maternal state sufficiently early in development to affect the pups. If the offspring of well- fed mothers are ready to be weaned at a certain age, the fact that access to solid food is artificially prevented will not have an effect on what has already started to take place within the pup. On the other hand, an early and abrupt termination of lactation will be too sudden to allow time for the pups to adjust their patterns of development. Our hypothesis that the timing of weaning is affected by local conditions, mediated through the mother's state, was suggested by the flexibility observed in animals that have to cope with a variable environment. This conclusion is clearly compatible with the results of laboratory studies showing that extrinsic factors such as steroid hormones and the presence of solid food in the intestine can accelerate the onset of sucrase activity (Lund and Smith 1987). What now needs to be added is that the onset may be delayed in poor conditions.

A striking aspect of our results was the manner in which the pregnant mothers prepared for the next litter. The Pregnant mothers started to put on weight many days before the growing foetuses could have contributed significantly to their weights. These mothers were likely to conceive around 24 hours following birth of their current pups, but gestation length was on average 28 days as compared with 21-22 days in non-lactating mothers. Pregnancy is extended in lactating rats 
because implantation may be delayed for up to ten days (McNeilly 1988) . The conclusion is that the Pregnant mothers in the present study put on weight before likely implantation of the embryos.

Even under good environmental conditions, some pups in a litter die. Mothers may neglect such pups in order to avoid losing too much weight and, thereby, providing sufficient nourishment for the surviving pups to gain weight above a minimum rate. In the current study, somewhat surprisingly, litter size reduction followed a broadly similar pattern in all groups.

It seems likely that if pregnant mothers had been food restricted, they would have given highest priority to the pups that were currently being nursed and their fertilised eggs would not have implanted. If that reasoning is correct, a pregnant mother signals to her pups not only that the weaning process will start early but also that environmental conditions are good. This means that the pups will be readily able to find solid food after weaning. On the other side, the food-restricted mother signals weaning will be delayed because conditions are bad and the pups will have difficulty in finding solid food after weaning.

What cues might the young have used to tune their weaning time to their mother's state? We did not find any evidence of a weight threshold; pups born to Food-restricted mothers do not express sucrase activity at weights when pups in the other two groups are doing so, and pups born to Pregnant mothers show higher sucrase levels at weights when Control pups show almost no sign of sucrase activity. Food restricted pups, however, showed significantly lower weights soon after food restriction started; although they did catch up later on, this difference in early development could have had long-term consequences for their mode of development. Even during stages in which there were no differences in pup body weight, maternal and offspring behaviour 
might have been different. In a study of cats by (Bateson et al. 1990), the kittens of food-restricted mothers demanded significantly more than those of control kittens by nuzzling the sides of their mother. Even though kittens of the food-restricted mothers put on weight at the same rate as the control kittens, they subsequently developed behaviourally in markedly different ways, which Bateson et al. (1990) suggested might be an adaptation to poor environmental conditions. Offspring may be able to gauge local conditions by the extent to which they have to work to get onto their mother's nipples (and perhaps how hard they have to work to obtain milk once on the nipple) before weaning. In the case of pups born to Pregnant mothers, pup body weight did not differ from that of controls at any stage. Pups must have used other cues such as evidence of maternal pregnancy, or differences in maternal behaviour. Smith (1991) found that Pregnant mothers spent more time with their pups up to day 18 . On day 18 , however, they abruptly changed their behaviour and retreated to a high shelf where they spent significantly more time than mothers in the other two groups. It seems likely, therefore, that the timing of weaning is affected first and foremost by cues derived from the mother and, to a lesser extent, by the pup's own stage of development, with heavier pups weaning earlier than lighter pups

The results from this study help to explain why conflicts of interest between mother and offspring do not necessarily translate into behavioural squabbles (Bateson and Gomendio 1992; Mock and Forbes 1992; Bateson 1994). Variations in environmental conditions and maternal state mean that the optimal for timing of weaning for both mothers and their offspring will vary from case to case. Mothers are evidently responsive to the needs of their offspring, as may be observed in rats when their pups are replaced by younger ones and they lactate for 
longer than would otherwise have been the case (Bruce 1958; Nicoll and Meites 1959) . For their part, the pups respond to maternal cues by adjusting their pattern of development. Pups do not spontaneously take solid food before they have reached a stage of development which is influenced by cues received from their mother. At the appropriate stage for the conditions in which the pups find themselves, a variety of changes in the gut are initiated, including the expression of the digestive enzyme sucrase. Offspring may benefit from being sensitive to maternal behaviour or condition, not only because they are ready to be weaned at the right time. By using these maternal cues, offspring may gain information about the surrounding environment in which they will have to live. When food availability is low, pups may switch to a slow developmental mode which not only includes delayed weaning, but also an altered patterns of behaviour at later stages of development. In contrast, maternal pregnancy may be used by pups as an indicator of food abundance and, under these conditions, pups switch to a rapid rate of development. The general point is that mothers and offspring seem to engage in a continuous exchange of information (Bateson 1992, 1994). When such dynamic negotiation occurs, the zone of potential conflict is narrowed greatly.

\section{Acknowledgements}

We are grateful for a grant from the Leverhulme Trust to Patrick Bateson and thank Peter James for technical assistance. Funding for visits between Madingley and the Museo Nacional de Ciencias Naturales was provided by a grant from the Acciones Integradas Ministerio de Educación y Ciencia-British Council. 


\section{References}

Abbey H, Howard E (1973) Statistical procedure in developmental studies on species with multiple offspring. Devl Psychobiol 6: 329-335

Altmann J (1983) Costs of reproduction in baboons (Papio cynocehalus). In: Aspey WP, Lustick SI (ed) Behavioral Energetics. Ohio State University Press, pp 67-88

Babbitt KJ, Packard JM (1990) Parent-offspring conflict relative to phase of lacation. Anim Behav 40: 765-773

Bateson P (1992) Parental care and offspring decisions about how to develop. In: Bateson P, Gomendio M (ed) Behavioural Mechanisms in Evolutionary Perspective. Instituto Juan March de Estudios e Investigaciones, Centro de Reuniones Internacionales Sobre Biología, Madrid, pp 87-88

Bateson P (1994) The dynamics of parent-offspring relationships in mammals. Trends Ecol Evol

Bateson P, Gomendio M (1992) Behavioural Mechanisms in Evolutionary Perspective. Instituto Juan March, Madrid Bateson P, Mendl M, Feaver J (1990) Play in the domestic cat is enhanced by rationing the mother during lactation. Anim Behav 40: $514-525$

Berger J (1979) Weaning conflict in desert and mountan bighorn sheep (Ovis candensis): an ecological interpretation. Z Tierpsychol 50: $188-200$

Bruce HM (1958) Suckling stimulus and lactation. Proc Roy SocLond B 149: 421-423

Cameron GN (1973) Effect of litter size on postnatal growth and surival in the desert wood rat. J Mammal 54: 489-493 
Clutton-Brock TH, Albon SD,Guiness FE (1988) Reproductive success in red deer. In: Clutton-Brock TH (ed) University of Chicago Press, Chicago, pp 325-343

Clutton-Brock TH, Albon SD, Guiness FE (1989) Fitness costs of gestation and lactation in wild mammals. Nature 337: 260-262

Clutton-Brock TH, Guiness FE, Albon SD (1982) Red Deer. University of Chicago Press, Chicago

Collinge NE (1987) Weaning variability in semi-free-ranging Japanese macaques (Macaca fuscata). Folia Primatol 48: 137-150

Dahlquist A (1960) Characterization of three different intestinal maltases. Acta chim Scand 13: 1659-1667

Festa-Bianchet M, Jorgenson JT, Wishart WD (1994) Early weaning in bighorn sheep, Ovis canadensis, affects growth of males but not of females. Behav Ecol 5: 21-27

Fuchs S (1981) Consequences of premature weaning on the reproduction of mothers and offspring in laboratory mice. Z Tierpsychol 55: 19-32

Fuchs S (1982) Optimality of parental investment: the influence of nursing on reproductive success of mother and female young house mice. Behav Ecol Sociobiol 10: 39-51

Godfray HCJ (1991) Signalling of need by offspring to their parents.

Nature 352: 328-330

Gomendio M (1991) Mother-offspring relationships and consequences for fertility in rhesus macaques. Anim Behav 42: 993-1005 Gomendio M, Clutton-Brock TH, Albon SD, Guiness FE, M.J. S (1990) Mamalian sex ratios and variation in the costs of rearing sons and daughters. Nature 343: 261-263 
Green WCH, Rothstein A (1991) Sex bias or equal opportunity?

Patterns of maternal investment in bison. Behav Ecol Sociobiol 29: $373-384$

Green WCH ,Griswold JG (1993) Weaning and parent-offspring conflict: variation relative to interbirth interval in bison. Ethology 95: $105-125$

Hauser M (1993) Do vervet monkey infants cry wolf? Anim Behav 45: $1242-1244$

Henning SJ (1981) Postnatal development: coordination of feeding, digestion, and metabolism. Amer J Physiol 241: G199-214 Henning SJ (1989) The role of hormones in the post-natal development of rat intestinal function. In: Smith M, Sepulveda FV (ed) Adaptation and development of gastrointestinal function. Manchester University Press, Manchester, pp 17-26

Johnson LR (1989) Postnatal development of rat gastric secretion. In: Smith MW, Sepulveda FV (ed) Adaptation and development of gastrointestinal function. Manchester University Press, Manchester, pp 27-39

König B, Markl H (1987) Maternal care in house mice. I. The weaning strategy as a means for parental manipulation of offspring quality. Behav Ecol Sociobiol 20: 1-9

Krackow S (1989) Effect of food restiction on reproduction and lactation in house mice mated post partum. J Reprod Fert 86: 341-347

Lee PC (1987) Nutrition, fertility and maternal investment in primates.

J.Zool. 213: 409-422

Lund EK, Smith MW (1987) Rat jejunal disaccharidase activity increases biphasically during early post-natal development. J Physiol 391: 487-497 
Markwell MAK, Haas SM, Bieber LL,Tolbert E (1978) A modification of the Lowry procedure to simplify protein determination in membrane and lipoprotein samples. Anal Biochem 87: 206-210

Martin P (1984) The time and energy cost of play behaviour in the cat. Z Tierpsychol 64: 298-312

Martin P (1986) An experimental study of weaning in the domestic cat. Behaviour 99: 221-249

McNeilly AS (1988) Suckling and the control of gonadotropin secretion. In: Knobil E ,Neill J (ed) The Physiology of Reproduction. Raven Press, New York, pp 2323-2349

Mock DW, Forbes LS (1992) Parent-offspring conflict: a case of arrested development. Trends Ecol Evol 7: 409-413

Nicoll CS, Meites J (1959) Prolongation of lactation in the rat by litter replacement. Proc Soc exp Biol Med 10: 81-82

Oftedal OT (1984) Milk composition, milk yield and energy output at eak lactation: a comparative review. Symp zool Soc Lond 51: 33-85

Prentice AM, Whitehead RG (1987) The energetics of human reproduction. Symp zool Soc Lond 57: 275-304

Smith EFS (1991) Early social development in hooded rats (Rattus norvegicus): a link between weaning and play. Anim Behav 41: 513-524

Thiels E, Cramer CP, Alberts JR (1988) Behavioral interactions rather than milk availability determine decline in milk intake of weanling rats. Physiol Behav 42: 507- 515

Trillmich F (1990) The behavioural ecology of maternal effort in fur seals and sea lions. Behaviour 114: 3-20

Trivers RL (1974) Parent-offspring conflict. Amer Zool 14: 249-264 
Gomendio et al

Table I. Amount of food (gr) given to food restricted mothers every day after parturition ( $75 \%$ of normal food intake).

Food restriction started on day 3 .

\begin{tabular}{|cc|}
\hline Day of lactation & Amount of food (gr/day) \\
\hline $3-5$ & 29.0 \\
$6-8$ & 30.6 \\
$9-11$ & 32.6 \\
$12-14$ & 35.5 \\
$15-17$ & 42.5 \\
$18-20$ & 44.1 \\
\hline
\end{tabular}


Gomendio et al

Table II. Number of pups sacrificed at different ages for the three experimental groups; the number of litters is shown in parenthesis.

\begin{tabular}{|cccc|}
\hline Age (days) & Control & Food restricted & Pregnant \\
\hline 12 & $8(2)$ & $8(2)$ & - \\
14 & $4(1)$ & $4(1)$ & - \\
16 & $6(2)$ & $7(2)$ & - \\
17 & $12(3)$ & - & $12(3)$ \\
18 & $20(6)$ & $8(2)$ & $12(3)$ \\
19 & $22(6)$ & $9(3)$ & $10(3)$ \\
20 & $14(5)$ & $15(5)$ & $8(2)$ \\
21 & $13(4)$ & $7(2)$ & $12(3)$ \\
\hline
\end{tabular}


Table III. Simple regression between $\log$ (sucrase activity +1$)(y)$ and $\log$ (pup body weight) (x) at different ages. Bonferroni correction applied. The day in which the sucrase scores showed the first detectable increase for each experimental group is indicated in bold lettering.

\begin{tabular}{|c|c|c|c|c|}
\hline Treatment & Day 18 & Day 19 & Day 20 & Day 21 \\
\hline Control & $\begin{array}{l}\mathrm{N}=20 \\
\mathrm{R}^{2}=0.002 \mathrm{~ns}\end{array}$ & $\begin{array}{l}\mathrm{N}=22 \\
\mathrm{R}^{2}=0.05 \mathrm{~ns}\end{array}$ & $\begin{array}{l}N=14 \\
R^{2}=0.29 n s\end{array}$ & $\begin{array}{l}N=13 \\
R^{2}=0.48 n s\end{array}$ \\
\hline Food restricted & $\mathrm{N}=8 \dagger$ & $\begin{array}{l}\mathrm{N}=9 \\
\mathrm{R}^{2}=0.27 \mathrm{~ns}\end{array}$ & $\begin{array}{l}N=11 \\
R^{2}=0.78 * *\end{array}$ & $\begin{array}{l}N=7 \\
R^{2}=0.60 n s\end{array}$ \\
\hline Pregnant & $\begin{array}{l}N=12 \\
R^{2}=0.66^{*}\end{array}$ & $\begin{array}{l}N=10 \\
R^{2}=0.0003 n s\end{array}$ & $\begin{array}{l}N=8 \\
R^{2}=0.44 n s\end{array}$ & $\begin{array}{l}\mathrm{N}=12 \\
\mathrm{R}^{2}=0.12 \mathrm{~ns}\end{array}$ \\
\hline
\end{tabular}

$$
* \mathrm{p} \leq 0.004, * * \mathrm{p} \leq 0.001, \mathrm{~ns} \mathrm{p}>0.004 \text {. }
$$

$\dagger$ Data for food restricted on day 18 reflect no sucrase activity in none of the 8 pups, so that no regression analysis could be carried out. 
Table IV. Average pup body weight $( \pm \mathrm{SE})$ for the three experimental groups around weaning. No significant differences were found (ANOVAs). The number of litters is shown in parenthesis.

\begin{tabular}{|ccccc|}
\hline Treatment & Day 18 & Day 19 & Day 20 & Day 21 \\
\hline Control & $26.81 \pm 1.16(8)$ & $27.35 \pm 1.38(10)$ & $31.34 \pm 1.44(7)$ & $31.50 \pm 1.41(5)$ \\
Food restricted & $27.19 \pm 4.03(3)$ & $25.97 \pm 1.82(8)$ & $26.66 \pm 1.93(12)$ & - \\
Pregnant & $31.45 \pm 1.71(5)$ & $30.00 \pm 1.96(6)$ & $28.38 \pm 2.45(7)$ & $32.06 \pm 4.33(3)$ \\
\hline
\end{tabular}




\section{FIGURE LEGENDS:}

Figure 1: (a) Food index for the three experimental groups around weaning (2-way ANOVA: Age(A): $\mathrm{df}=2, \quad \mathrm{~F}=9.02, \quad \mathrm{p}=0.0002$; Experimental $\operatorname{group}(\mathrm{B}): \mathrm{df}=1, \mathrm{~F}=34.29, \mathrm{p}<0.0001 ; \mathrm{AB}: \mathrm{df}=6, \mathrm{~F}=0.78$, N.S.) (control vs food restricted: $\operatorname{Age}(\mathrm{A})$ : $\mathrm{df}=2, \mathrm{~F}=11.52, \mathrm{p}<0.0001$; Experimental group(B): $\mathrm{df}=1, \mathrm{~F}=32.78, \mathrm{p}<0.0001 ; \mathrm{AB}: \mathrm{df}=2, \mathrm{~F}=1.67$, N.S.; control vs pregnant: Age(A): $\mathrm{df}=4, \quad \mathrm{~F}=40.35, \mathrm{p}<0.0001$; Experimental $\operatorname{group}(\mathrm{B}): \mathrm{df}=1, \mathrm{~F}=10.84, \mathrm{p}=0.001 ; \mathrm{AB}: \mathrm{df}=4, \mathrm{~F}=3.02$, $\mathrm{p}=0.02)$. Asterisks indicate overall significant differences between control and the other two groups; whereas the encircled symbols refer to particular differences between control and the other two groups on some days.

(b) Sucrase activity for the three experimental groups around weaning (2-way ANOVA: Age(A): $d f=3, \quad F=25.25, \quad p<0.0001$; Experimental group(B): $d f=1, F=71.52, p<0.0001 ; A B: d f=7, F=10.13$, $\mathrm{p}<0.0001$ ) (control vs food restricted: $\operatorname{Age}(\mathrm{A})$ ) $\mathrm{df}=3, \mathrm{~F}=18.95, \mathrm{p}<0.0001$; Experimental group $(B): \mathrm{df}=1, \mathrm{~F}=37.56, \mathrm{p}<0.0001 ; \mathrm{AB}: \mathrm{df}=3, \mathrm{~F}=11.35$, $\mathrm{p}<0.0001$; control vs pregnant: $\operatorname{Age}(\mathrm{A})$ : $\mathrm{df}=4, \mathrm{~F}=37.78, \mathrm{p}<0.0001$; Experimental group $(B): \mathrm{df}=1, \mathrm{~F}=56.42, \mathrm{p}<0.0001 ; \mathrm{AB}: \mathrm{df}=4, \mathrm{~F}=10.59$, $\mathrm{p}<0.0001)$. Asterisks indicate overall significant differences between control and the other two groups; whereas the encircled symbols refer to particular differences between control and the other two groups on some days.

Figure 2: Relationship between $\log ($ sucrase activity +1 ) and food index (regression analysis: $\mathrm{N}=172, \mathrm{R}^{2}=0.45, \mathrm{p}<0.0001$ ).

Figure 3: Relationship between standardised sucrase activity at the onset of weaning and standardised pup body weight on day 3 (regression analysis: $\left.\mathrm{N}=28, \mathrm{R}^{2}=0.47, \mathrm{p}<0.0001\right)$.

Figure 4: (a) Average pup body weight for the three experimental groups up to weaning (RMANOVA: Age $(\mathrm{A})$ : $\mathrm{df}=5, \mathrm{~F}=568.74, \mathrm{p}<0.0001$; Experimental group(B): $\mathrm{df}=2, \mathrm{~F}=3.44, \mathrm{p}=0.045 ; \mathrm{AB}: \mathrm{df}=10, \mathrm{~F}=1.39$, N.S.) (control vs food restricted: $\operatorname{Age}(\mathrm{A})$ : $\mathrm{df}=5, \mathrm{~F}=413.93, \mathrm{p}<0.0001$; Experimental group(B): $\mathrm{df}=1, \mathrm{~F}=2.94$, N.S.; $\mathrm{AB}: \mathrm{df}=5, \mathrm{~F}=1.01$, N.S.; control vs pregnant: Age $(\mathrm{A})$ : $\mathrm{df}=5, \mathrm{~F}=510.93, \mathrm{p}<0.0001$; Experimental $\operatorname{group}(\mathrm{B}): \mathrm{df}=1, \mathrm{~F}=1.79$, N.S.; $\mathrm{AB}: \mathrm{df}=5, \mathrm{~F}=0.92$, N.S.). Encircled symbols indicate significant differences with the control group.

(b) Maternal body weight for the three experimental groups up to weaning (RMANOVA: Age $(\mathrm{A})$ : $\mathrm{df}=5, \mathrm{~F}=39.93, \mathrm{p}<0.0001$; Experimental 
$\operatorname{group}(B): \mathrm{df}=2, \mathrm{~F}=16.38, \mathrm{p}<0.0001 ; \mathrm{AB}: \mathrm{df}=10, \mathrm{~F}=9.05, \mathrm{p}<0.0001)$ (control vs food restricted: Age $(\mathrm{A})$ : $\mathrm{df}=5, \mathrm{~F}=16.06, \mathrm{p}<0.0001$; Experimental group $(B): d f=1, F=18.15, p=0.0003 ; A B: d f=5, F=11.97$, $\mathrm{p}<0.0001$; control vs pregnant: $\operatorname{Age}(\mathrm{A})$ : $\mathrm{df}=5, \mathrm{~F}=47.71, \mathrm{p}<0.0001$; Experimental $\operatorname{group}(B): \mathrm{df}=1, \mathrm{~F}=2.29$, N.S.; $\mathrm{AB}: \mathrm{df}=5, \mathrm{~F}=1.10$, N.S.). Encircled symbols indicate significant differences with the control group.

Figure 5: Litter size for the three experimental groups up to weaning (RMANOVA: Age(A): $\mathrm{df}=5, \quad \mathrm{~F}=56.33, \quad \mathrm{p}<0.0001 ;$ Experimental $\operatorname{group}(B): \mathrm{df}=2, \mathrm{~F}=0.32$, N.S.; $A B: \mathrm{df}=10, \mathrm{~F}=6.72, \mathrm{p}<0.0001)$. 
Gomendio et al

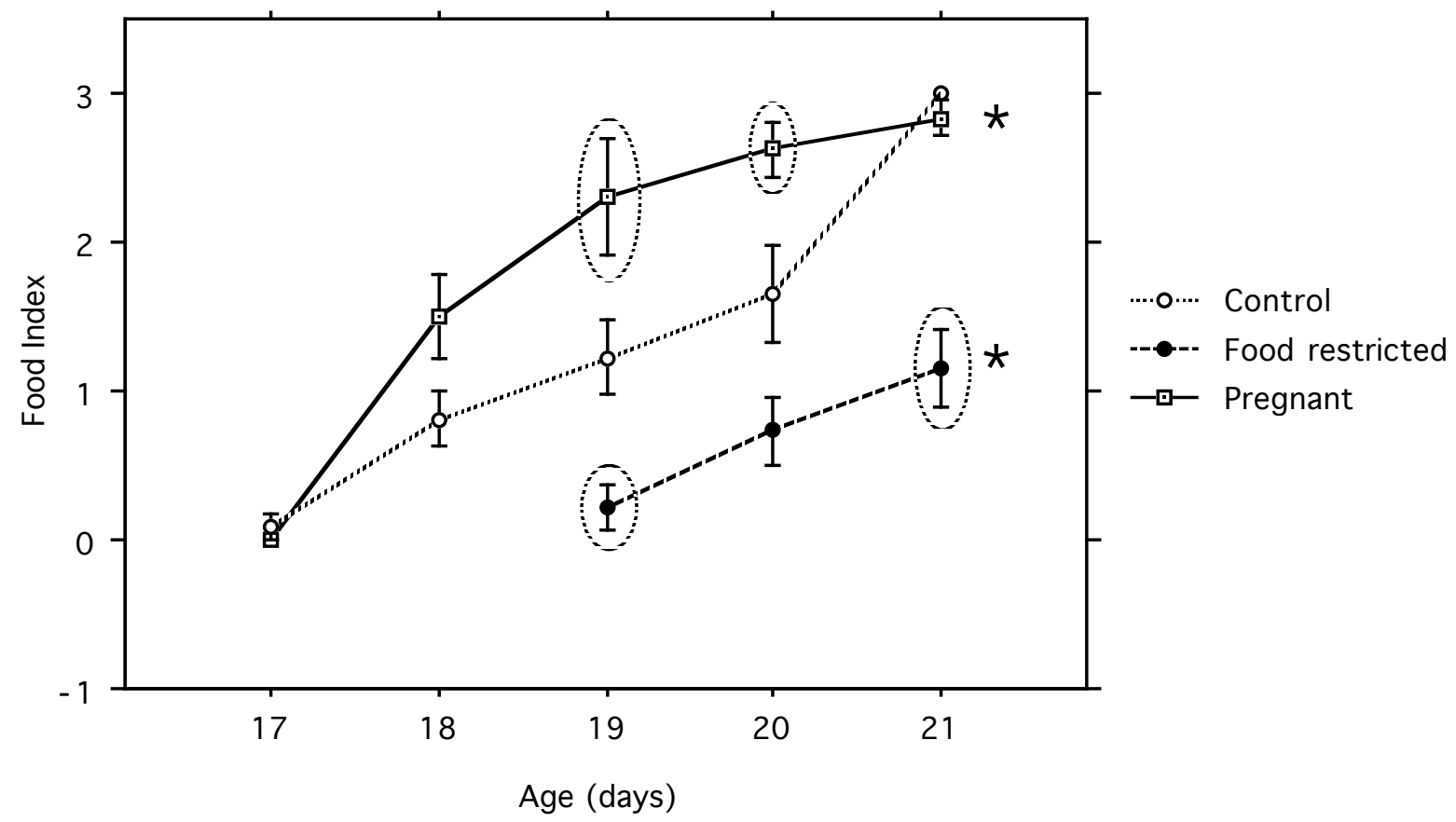

FIG. 1A 
Gomendio et al

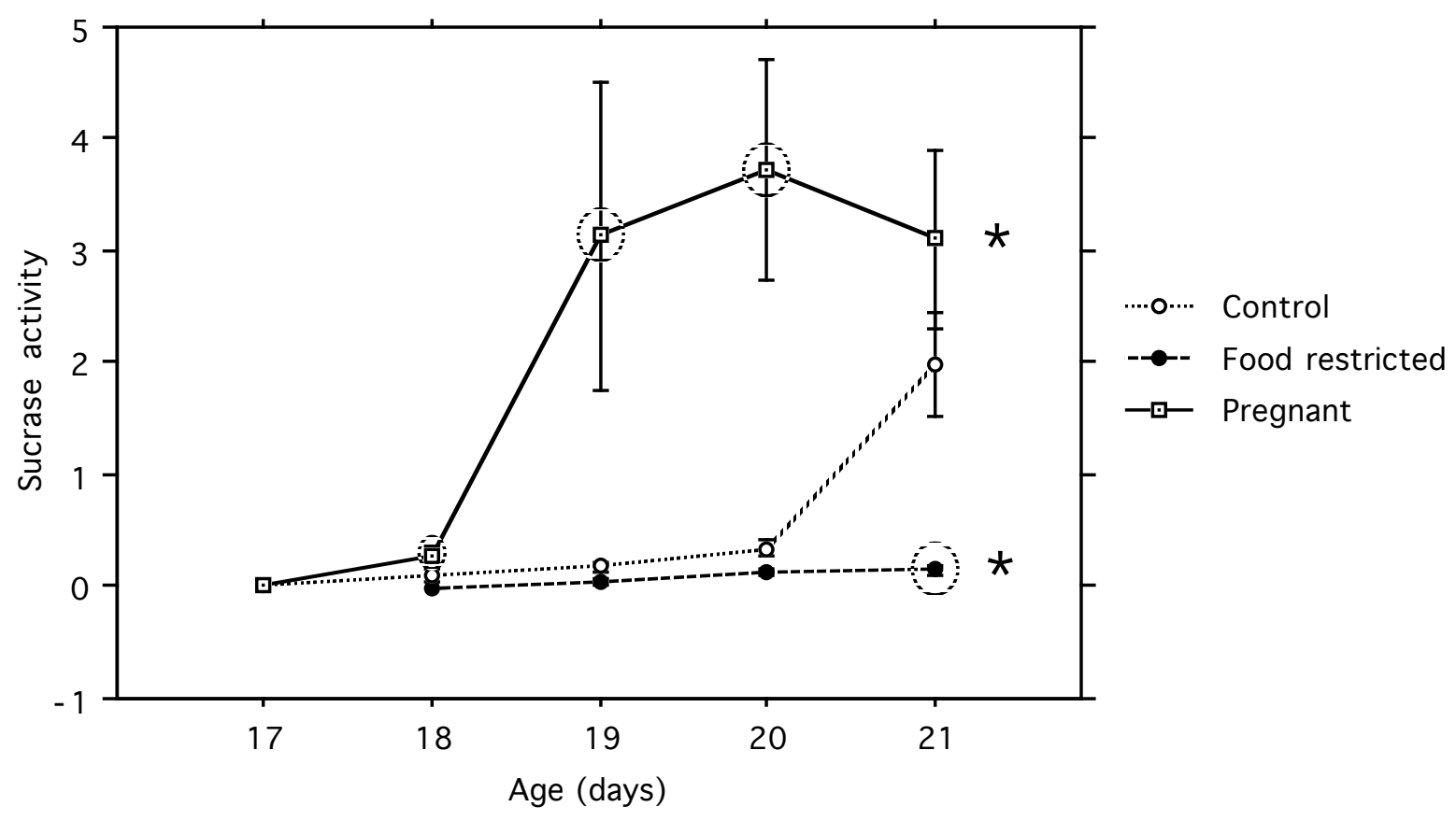

FIG. 1B 
Gomendio et al

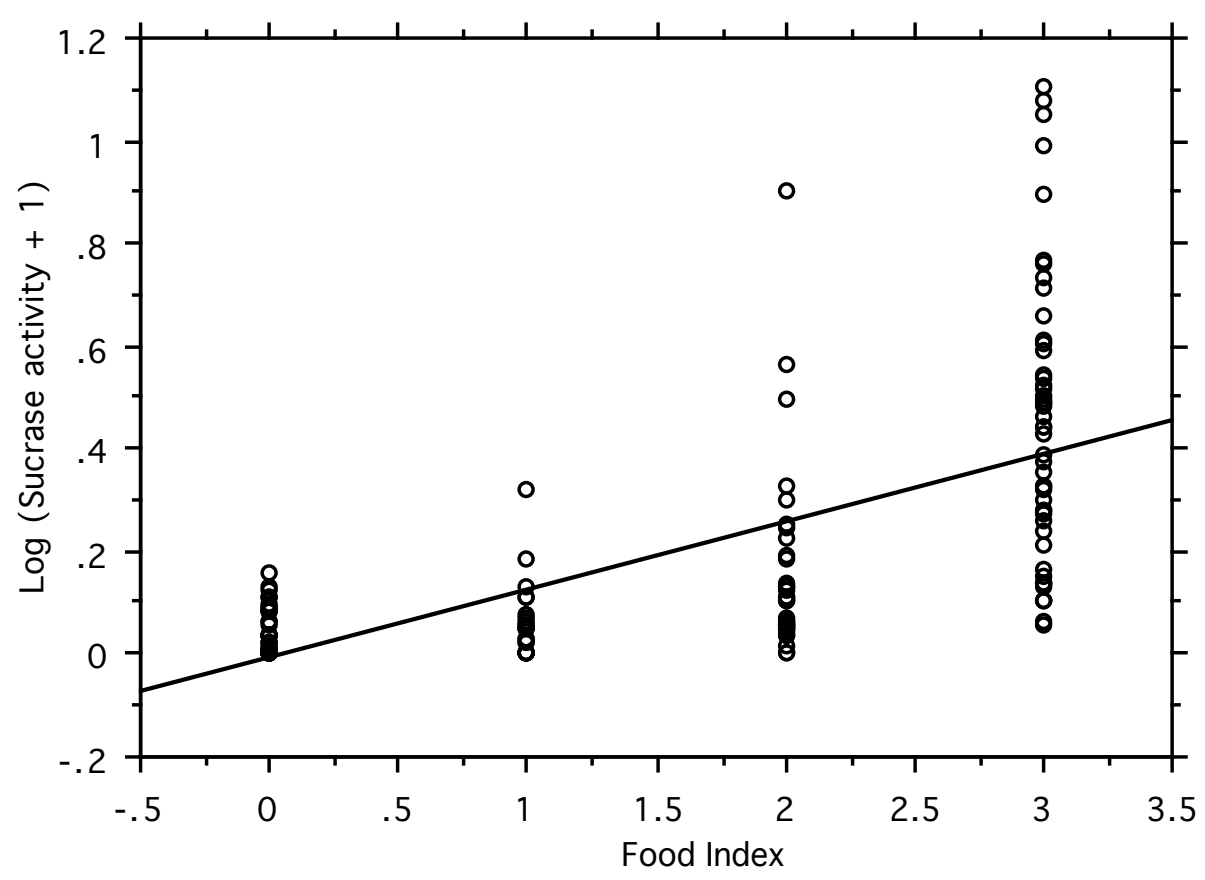

FIG. 2 
Gomendio et al

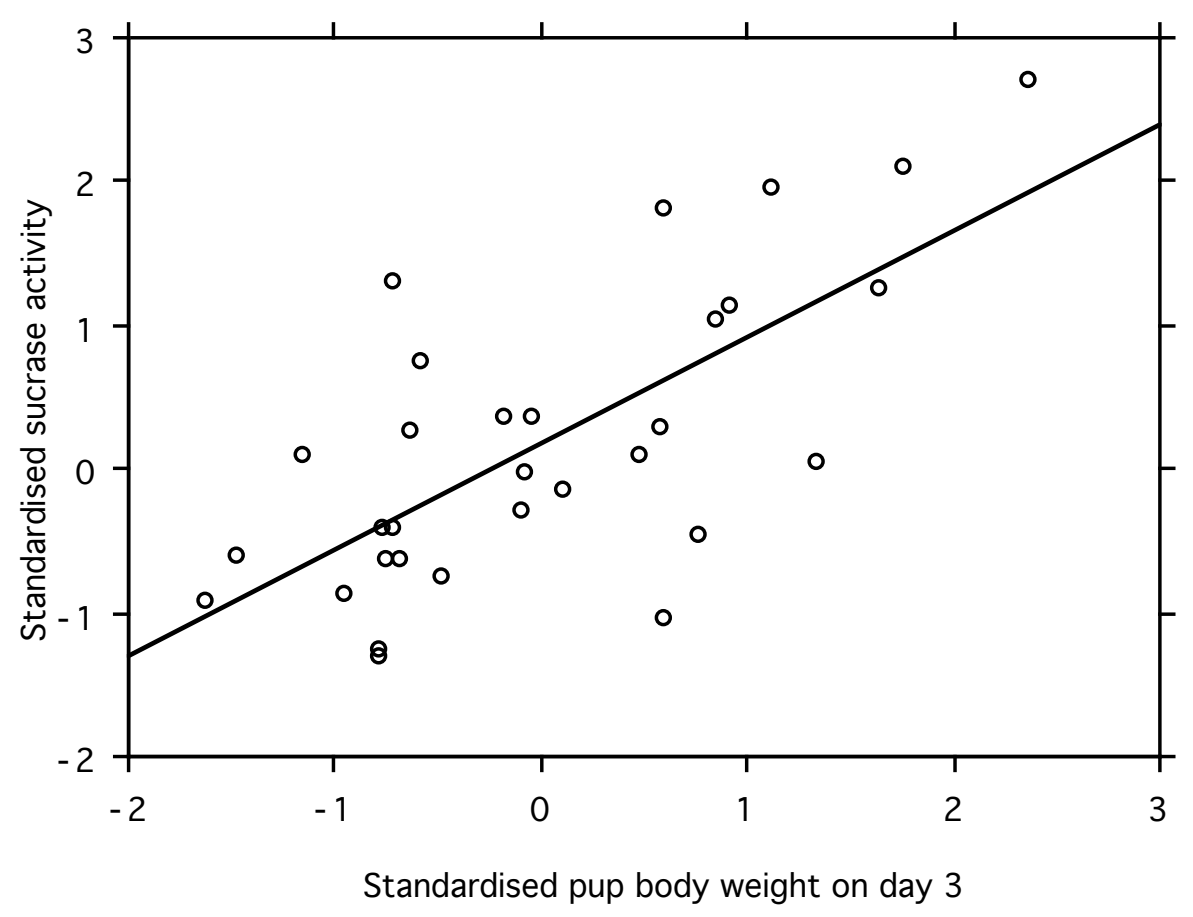

FIG. 3 
Gomendio et al

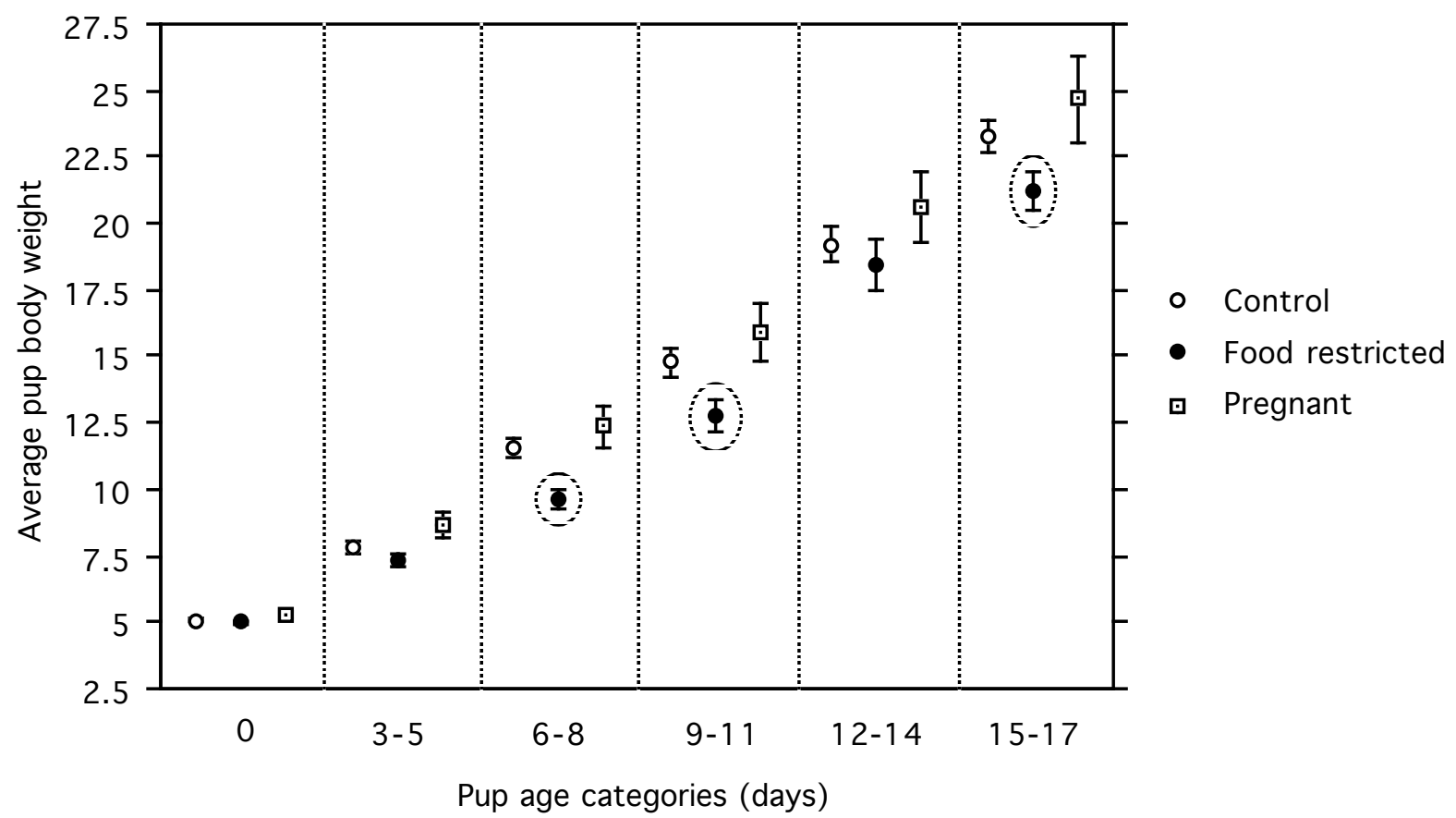

FIG. 4A 
Gomendio et al

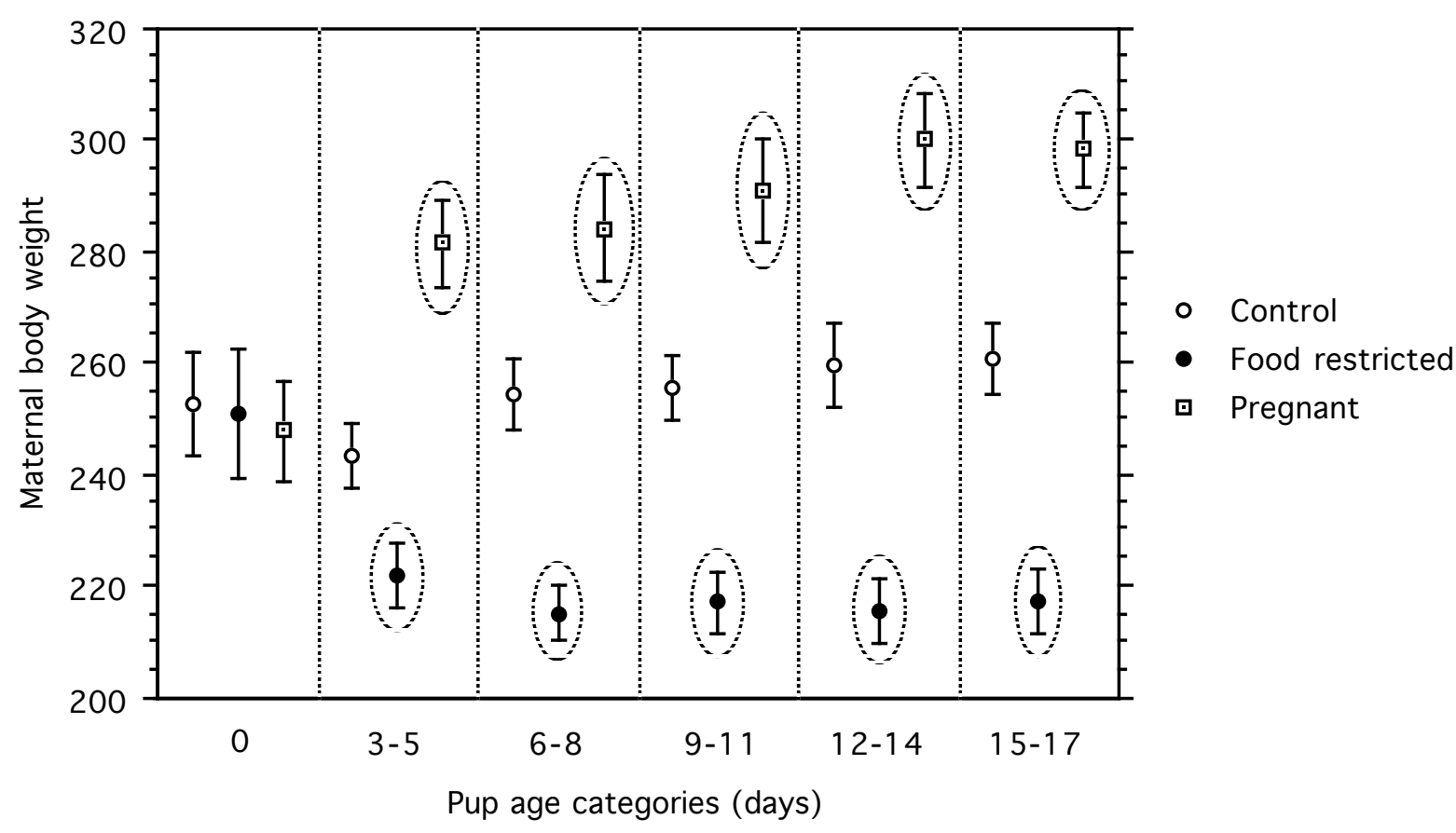

FIG. 4B 
Gomendio et al

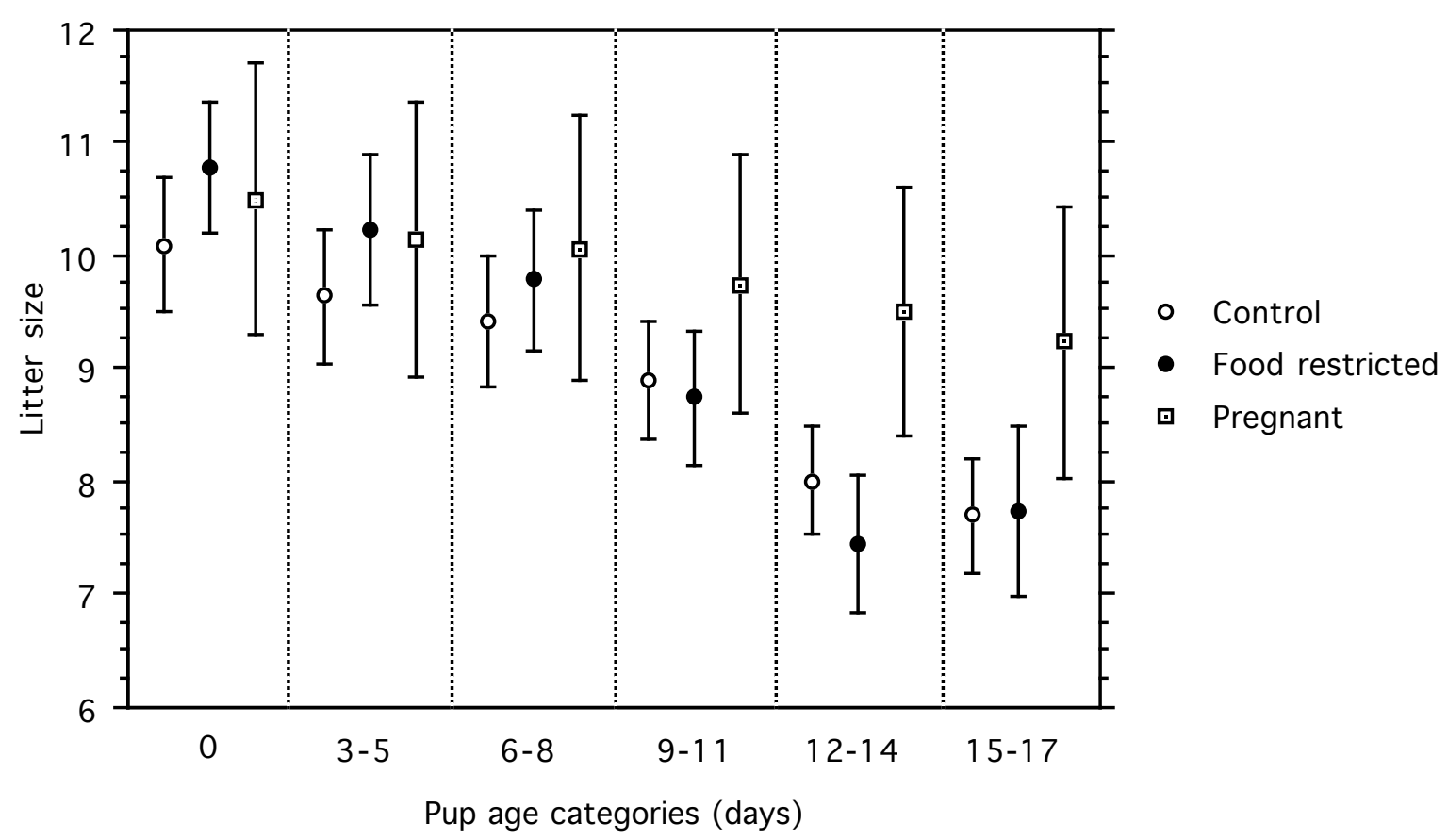

FIG. 5 